\title{
SERVIÇOS
}

O AUTOR

Marco Antônio Xavier

Mestre em História Social, pela FFLCH-USP e

Especialista em Museologia, pelo MAE-USP. Curador do Memorial do Imigrante, da Secretaria de

Estado da Cultura de São Paulo.

\section{MEMORIAL DO IMIGRANTE - UM MUSEU EM MOVIMENTO}

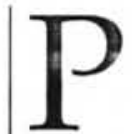

ara muitas pessoas, em especial professores e alunos, a única função de um museu é ensinar. Ensinar a ler uma obra de arte, a compreender um fato histórico, a divulgar a Ciência etc.

Um museu é isso, mas não se resume só a isso.

A capacidade de alguns museus de cumprirem suas missões ${ }^{1}$ é essencial para alcançarem uma de suas metas, que é ensinar. Aqui cabe também uma outra diferenciação.

Ensinar, sob meu ponto de vista, é fazer com que uma determinada mensagem chegue aos indivíduos, promovendo um avanço nos seus conhecimentos, de maneira que eles possam, a partir disso, relacionar o que aprenderam com suas memórias e seus sentimentos, comparando-os com experiências anteriores, gerando questionamentos. Como está escrito no Aurélioº : "Transmissão de conhecimento, de informações ou de esclarecimentos úteis ou indispensáveis à educação ou a um fim determinado". No latim, o termo "insignare" significa: dar instrução sobre, fazer conhecer.

Desta forma, um determinado operário aprende sobre seu trabalho com os companheiros mais experientes, tornando-se um especialista, enquanto outro trabalhador aprende sobre política trabalhista na porta da fábrica. São experiências diferentes, mas não excludentes, que acabam por fazer de cada ser humano uma manifestação única de conhecimentos e atitudes.

Paralela a essa definição, está o ato de educar que - volto a afirmar minha forma particular de ver esse fenômeno - se diferencia

1. Ou pelo menos daqueles que estão se adaptando às questões do terceiro milênio, sem esquecer de sempre rever suas metas.

2. FERREIRA, Aurélio Buarque de Holanda. Novo Dicionário da Língua Portuguesa. Rio de Janeiro: Nova Fronteira, 1975. 
do ato de aprender por ser uma atividade sistemática e estruturada, com determinada finalidade e alcance, estipulando metas e diferenciando grupos de indivíduos. Para isto, na educação formal, temos os currículos, as metas programáticas, as classes, as aferições de conhecimento, as promoções e os níveis de escolaridade, que acabam por criar uma falsa hierarquia do conhecimento. Novamente, segundo o Aurélio: "Processo de desenvolvimento da capacidade física, intelectual e moral... do ser humano... visando à sua melhor integração individual e social"3. .

A escola usa as duas formas, o museu só a primeira. São essas diferenças que fazem com que os museus não estejam voltados exclusivamente para educar, mas para ensinar. Eles não devem ser uma extensão da escola, um simples complemento. Eles devem ter sua própria identidade, que pode ser compartilhada e usufruída pelos estudantes e professores. Mesmo os museus universitários, que na sua origem tinham uma função didática, hoje abrem seus acervos e pesquisas para o público em geral.

Se formos analisar, de maneira estritamente técnica, a função primordial de um museu é a preservação de um patrimônio, sendo este definido em relação ao ser humano como produtor ou agente num determinado ambiente.

Como diz uma amiga: por que as pedrinhas que eu junto, quando viajo, são diferentes dos objetos líticos, coletados numa expedição? $\mathrm{Na}$ verdade, não são diferentes, por se tratar de fragmentos de rochas encontradas na natureza, mas as razões que levaram cada um a escolher este ou aquele são o fator de singularidade. En- quanto, talvez, ela escolha por razões de forma, textura ou coloração, segundo uma experiência pessoal e estética, um cientista verá, nessas mesmas formas, texturas e colorações, uma particularidade físico-química ou de alguma ação humana. Poucas pessoas vêem a diferença entre uma ponta de flecha de um período longínquo no passado e uma lasca que acabou de se desprender do solo. Veja bem, não estamos falando de valoração de um ou outro método, mas tão somente das diferentes atitudes e experiências com o mesmo mundo que nos cerca.

Um museu é um lugar de preservação de um patrimônio que tem alguma relação com o ser humano, seus atos, vontades e como ele encara a natureza. Se precisa preservar, deve ter um espaço delimitado e próprio para isso.

Mas porque devemos preservar? Ao preservarmos alguma coisa, não importa, em essência, por quanto tempo, esperamos que as informações que aquele objeto carrega possam ser percebidas por outras pessoas. Nesse sentido, o museu ensina tanto aos que nele trabalham (pesquisadores, funcionários, técnicos, dirigentes etc.) quanto aos que dele participam - seu público -, independentemente de ele ser passivo ou ativo no processo de comunicação. 
Acho errado esperar que museus sigam os currículos escolares, independentemente de seu público ser, em grande parte, formado por alunos. Isto tiraria a pluralidade de visões de mundo, que é própria da atividade museal. Museus devem conservar, não serem conservadores. É perfeitamente lógico, e legítimo, que um professor, ao levar seus alunos para um museu, queira ver e mostrar algo que ilustre o que foi ou será tratado em classe, mas esta atitude não pode determinar a escolha dos acervos ou o tratamento expositivo dado a eles. A função complementar dos museus, na educação formal, nunca atingirá $100 \%$ em relação às expectativas, por mais que uma exposição seja bem concebida, estruturada e montada. Soma-se a isso a necessidade de os museus atingirem vários públicos. Um museu que se limita a determinada freqüência, sem novos aspectos abordados sobre o acervo, ou seja, enrijecido e limitado, está decretando sua própria morte, e com ele a morte do acervo. Nesse caso, a preservação não se efetivou pela falta de comunicação entre os interessados, exercendo o acervo a função de escrita, nessa linguagem. Para o público, ler o mesmo texto, sempre, não acrescenta nada às suas vivências, pelo contrário, afasta a mensagem do objeto.

\section{MUSEU: DEPÓSITO DE COISAS VELHAS?}

Mas há alguma forma de minimizar esta discrepância entre os objetivos dos museus e a vontade e a expectativa do público? Talvez sim, se conseguirmos explicar o porquê da existência e como funcionam os museus. Para isso, costumo

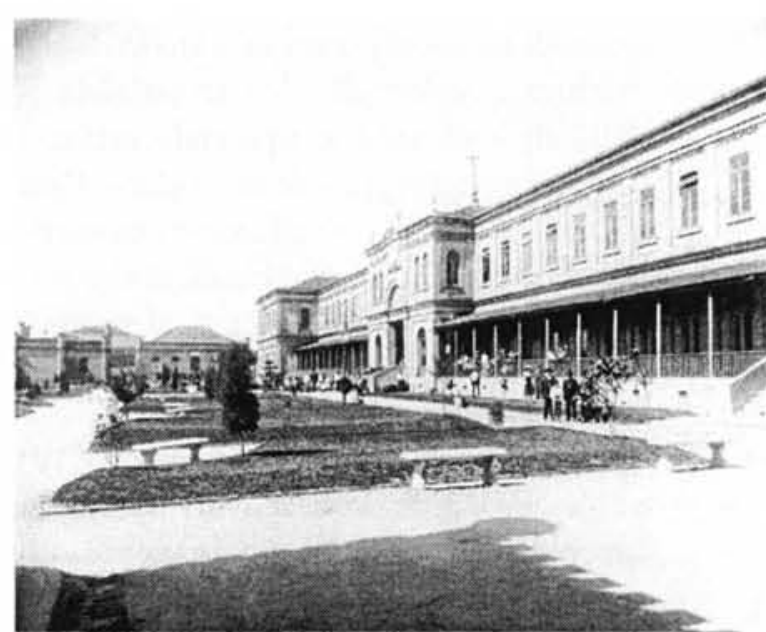

Fachada da Hospedaria de Imigrantes, cerca de 1915.

partir da noção mais comum e, de certa maneira, pejorativa, que as pessoas têm de museus: um depósito de coisas velhas.

Essa frase, mencionada e repetida por várias pessoas, em vários lugares do mundo, não está de todo errada. Apenas devemos compreender e definir cada um dos termos usados, acrescentando sentido a eles, para mudar a forma de as pessoas encará-los.

Um depósito - sim, um museu é depósito onde pretendemos guardar alguma coisa, geralmente que tenha a ver com a nossa vida (portanto, numa relação com o ser humano). Quando guardamos alguma coisa, estamos pensando em utilizá-la em algum outro momento, reservando-a onde podemos encontrá-la quando desejarmos. É certo, algumas outras vezes essas coisas perdem o sentido inicial que atribuímos a sua preservação, mas se lembrarmos, seja pela memória (que é reconstruída sempre), seja por alguma anotação (que dificilmente muda), da razão de guardarmos aquele objeto, então ele terá cumprido sua missão de carregar 
uma mensagem no tempo. Pensamos mais uma vez, desta vez avançando no tempo, e imaginamos se iremos precisar daquele objeto. Como prever o futuro é algo impossível (apesar de algumas pessoas acharem que é factível), acabamos por manter aquele objeto por mais algum tempo. Se esquecermos aquela necessidade inicial em preservá-lo, sem nenhuma referência em que nos basearmos, aí não há razão de continuar a manter o objeto. Com os museus ocorre da mesma forma. Guardamos os objetos com determinada finalidade, seja de testemunho, seja para futuras pesquisas, seja por deleite estético, seja para manter ou relembrar uma estrutura social. Mas se não tivermos consciência do motivo que nos fez retirar esse objeto do uso cotidiano, por que o preservamos, por que o guardamos em determinado lugar (nos museus são os objetos sem identificação de origem, procedência, função etc.), então qual a razão de continuar mantendoos? Os museus, ao contrário das pessoas, quase nunca se desfazem de seus acervos, porque buscam ajuda em seus pares e similares. Se eu não sei, alguém talvez saiba.

O problema do depósito, do local de guarda, disponibilidade e preservação dos objetos (no caso do museu, de seu acervo), está resolvido.

Agora vem a palavra coisas, que pode ser qualquer... coisa.

$\mathrm{O}$ que irá para o depósito (museu), a partir dessa definição, pode ser uma infinidade de objetos, produzidos pelo homem ou encontrados na natureza. É uma questão de escolha. Um acervo (de museu) é fruto de uma seleção criteriosa (ou deveria ser) dos objetos que têm relação com a temática do museu. Não existe museu de uma peça só. Uma peça, ou objeto, mais valioso ou conhecido, sempre mantém uma relação com os outros. Eles contam uma história, transmitem uma mensagem, nos fazem sentir algo. E aquela relação com o ser humano, indissolúvel, nos traz, mesmo nos objetos mais estranhos à nossa vivência e cultura, uma familiaridade.

\section{Algo totalmente novo, que não possa ser descrito ou compreendido, não tem lugar na mente do homem. Mesmo a estranheza busca basear-se em
alguma experiência anterior.}

Nenhum objeto, ou coisa parecida, vai sozinho para dentro de um museu. O processo que os torna patrimônio é um ato de escolha, apoiado em alguns pressupostos, fatos e idéias. Mas isso não invalida ou legitima completamente o ato de escolher, ou seja, separar uma parte do todo, por questões de esta parte representar o todo ou ser diferente dele. Percebemos que o que irá para dentro de um museu é uma parcela do mundo, uma representação de uma realidade maior. Se uma das funções do museu é ensinar, ele deve deixar claro as razões dessa escolha, o que, convenhamos, não é tarefa fácil. Essa explicação do objeto também não pode ser um laudo técnico, pois a linguagem e o tipo de informação estará subtraindo a informação principal - a razão de preservarmos este objeto. Quando digo objeto estou me referindo a coisas, materiais e imateriais. $\mathrm{O}$ objeto imaterial, de qualquer modo, pre- 
cisa de um meio físico pelo qual ele possa ser guardado. Esse meio pode ser a memória das pessoas, que, na verdade, reconstrói esta coisa, ou uma gravação, ou um texto que se refere a ela. Alguém pode dizer: "Então, os museus virtuais cuidam de objetos imateriais!?". Os museus virtuais são uma forma de divulgação do acervo, mas só em alguns casos podem ser considerados pela função de preservação. Eles não mantêm inalteradas as características do objeto material, como sua individualidade e contexto, porque não garantem a sua integridade física. Há muitos museus reais que possuem sites ou páginas na rede virtual, mas isso não lhes dá o direito de se desfazerem do seu acervo material.

$\mathrm{O}$ último termo daquela frase - velhas - não deve ser tomado ao pé da letra. Velho, no caso da maioria dos objetos, é uma simplificação de fora de uso. Quando alguma coisa passa a compor o acervo de um museu, ela é retirada do circuito de uso cotidiano ou no qual estava inserida. Este isolamento de onde era usado esse objeto não implica a exclusão de seu papel em determinada situação e contexto cultural, ou de sua importância. Afinal, sua escolha fez dele um ícone, algo que representa muito mais do que sua figura, seu significado inicial, sua presença física. Ele é a representação de outros iguais a ele e, em alguns casos, mesmo de seus antagonistas ou antônimos. Esta retirada do objeto de seu meio não acontece em todos os casos, mas este isolamento, este distanciamento do cotidiano é quase uma constante. Os museus devem ter a preocupação de que esta separação entre a existência do objeto, antes inseri- do num contexto de relações, e a sua incorporação como acervo sofra as mínimas perdas possíveis, pois a razão de ser do objeto, e de sua escolha pelo museu, reside necessariamente nas várias relações que ele mantinha com a realidade de seu tempo e espaço.

\section{MEMORIAL DO IMIGRANTE}

O Memorial do Imigrante não é somente um museu, mas um complexo de serviços culturais com base no seu acervo, basicamente composto por objetos de uso cotidiano, de imigrantes e seus descendentes, ou com alguma relação relevante com a história da imigração para o Brasil e, particularmente, São Paulo. Mas esse acervo também conta com imagens, em geral fotografias, livros e periódicos, documentos oficiais e pessoais, além de depoimentos de imigrantes em vídeo.

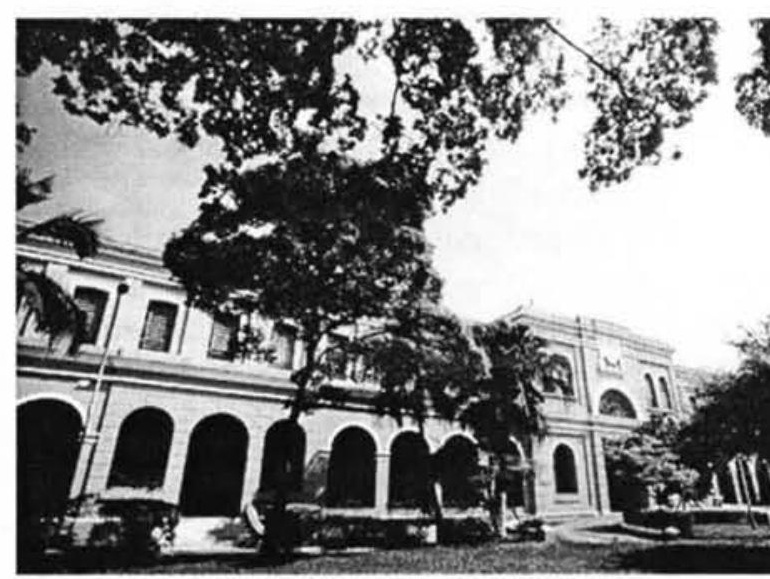

O Memorial do Imigrante, atualmente

Grande parte do nosso público, especialmente no período letivo, é composta por estudantes das mais variadas procedências. Escolas públicas e privadas (na 
maioria) trazem seus alunos para uma visita ao Memorial com a dupla finalidade de promover uma atividade extraclasse e, mais que ilustrar os tópicos abordados nas aulas de História do Brasil contemporâneo, introduzir aquelas crianças e adolescentes em ambiente de um museu que, ouso dizer, é diferenciado de outras experiências que tiveram.

Começa pela localização do museu, na porta de entrada da Zona Leste da cidade, tão carente de centros e atividades culturais para uma população, muitas vezes, marginalizada e esquecida pelos governantes. Como o Memorial ocupa o antigo edifício da Hospedaria de Imigrantes, construído entre 1886 e 1888 , e primeiro endereço de mais de 2,5 milhões de imigrantes, de mais de 60 nacionalidades, os professores podem começar a visita por uma análise da localização da Hospedaria, encravada entre duas ferrovias e num antigo bairro operário e industrial (na verdade na divisa entre Brás e Mooca). Em seguida, pode perguntar aos alunos sobre suas origens, questionando, em especial, aqueles que não têm certeza sobre seus ascendentes: Meu avô era português? Minha avó era judia? Meus tataravós eram escravos? De onde vem meu sobrenome?

Esses tipos de perguntas criam uma curiosidade que pode e deve ser usada, pois ela é a ligação entre a temática do museu e o público, no caso os alunos (e mesmo alguns professores). Imaginar que algum parente, no passado, passou por aquele lugar, cria um reconhecimento nas pessoas, que as exposições tentarão explorar através dos textos, fotos, objetos e outras atividades.
A sua história está presente no museu, não num passado distante e irreconhecível. Costumo brincar dizendo que o Memorial é uma máquina do tempo, como a luz das estrelas, pois o que vemos hoje é aquilo que restou do passado.

Outro fator de reconhecimento é a composição básica do acervo. Ele deve ser um retrato da vida destes imigrantes, suas conquistas e lutas, suas derrotas e esperanças. Desta forma, não pode se distanciar do cotidiano das pessoas comuns, tanto no campo como nas cidades. Quanto ao núcleo rural do acervo, devemos dizer, ele é o que mais causa estranheza nos estudantes, devido ao caráter diverso da realidade deles; muitos nunca haviam visto um pé de café ou uma casa com telhado de sapé. De qualquer maneira, acaba havendo um acréscimo ao conhecimento dessas pessoas, que enfim podem fazer uma comparação com um modo de vida diferente.

Para manter a integridade do acervo, em relação à temática, é necessária uma política de aceite para as doações. O Memorial do Imigrante não adquire seu acervo por compra, somente por doações e empréstimos. Isso devido a duas razões: a primeira diz respeito ao orçamento apertado, que nos permite manter o acervo atual, com uma pequena margem para expansão, sem sobra para gastos com aquisições; a segunda, e mais importante, é o posicionamento diante do comércio de antigüidades e obras 
de arte, uma atividade legítima (quando feita de forma responsável), mas que exclui a participação do proprietário dessas peças como um doador, cumprindo um papel ativo na cidadania de um país em vias de desenvolvimento ou emergente. Grandes museus do primeiro mundo têm valiosas peças de seu acervo doadas por proprietários e mecenas. As razões que fazem essas pessoas doarem esses objetos a um museu (vaidade, filantropia, promoção pessoal, etc.) ou a forma (legal) pela qual as adquiriram, não cabem neste texto.

Para um objeto vir a fazer parte do acervo do Memorial, como disse anteriormente, ele deve estar ligado a alguma das temáticas abordadas, assim como manter uma relação com as demais peças. A história desses imigrantes, de suas vidas é contada pela interação desses fatores. Mais uma vez, trata-se do uso do objeto museológico como um texto no discurso do museu.

Além da própria relação entre as peças, dentro de uma coleção $0^{4}$, há a necessidade de que façam parte de um conjunto maior, configurando um grupo temático expositivo. Dessa forma, objetos, fotos e documentos que tenham relação com as atividades profissionais dos imigrantes, na indústria, no comércio, nos serviços e no trabalho no campo, ficam expostos numa sala chamada Com o suor de seu rosto. Uma outra sala, Ambientes da Hospedaria, possui objetos usados na Hospedaria de Imigrantes, pelos que ali chegaram em diversas épocas, e as práticas de controle e registro dessas pessoas. Essas salas são exemplos das exposições de longa dura- ção ${ }^{5}$, mas há outras, chamadas temporárias, que permitem abordar temas mais específicos e relacionados a algum grupo de imigrantes ou a acontecimentos históricos e culturais.

Neste ponto vale a pena mais uma explicação. Nenhuma das salas de exposições de longa duração são centradas em apenas um grupo (ou nacionalidade) de imigrantes. Isto é feito para evitar privilegiar aquelas correntes migratórias maciças, como os italianos, os portugueses, os espanhóis, os alemães, os japoneses e algumas outras, responsáveis por quase $90 \%$ dos imigrantes que aqui chegaram, em detrimento de grupos como poloneses, egípcios, peruanos, angolanos etc. Estes últimos, embora sejam de menor expressão numérica, são tão importantes quanto aqueles outros na formação de nossa sociedade e no amálgama cultural de São Paulo.

Mas não há somente exposições temporárias sobre as comunidades. Aspectos relacionados a imigração ou temas históricos, que expliquem e elucidem as razões das migrações ao longo do tempo, têm uma atenção especial. Já foram tratados, especificamente, o trabalho feminino, os movimentos grevistas de 1917, as mudanças pelo qual o mundo passou na virada dos séculos XIX e XX, entre outros.

\section{O complexo de serviços}

culturais e sociais do Memorial do Imigrante inclui outras atividades além do Museu da Imigração. 
Há um Núcleo Histórico dos Transportes, responsável por estudar e preservar os meios de transporte e sua relação com a mobilidade de pessoas e mercadorias, baseado no trinômio café-ferrovia-imigração (produto, transporte e mão-de-obra). O Núcleo de Estudos e Tradições procura manter algumas atividades e práticas culturais dos imigrantes e seus descendentes, dando apoio informal a várias associações e grupos folclóricos, servindo como referencial e espaço aberto para discussões e encontros, além de promover manifestações de caráter histórico e cultural. Por fim, o Centro de Pesquisa e Documentação é responsável pela guarda e disponibilização para pesquisa dos documentos (oficiais e pessoais) relativos aos imigrantes que passaram pela Hospedaria, além de uma biblioteca especializada no tema imigração e migrações, dando apoio aos mais variados estudos e trabalhos acadêmicos sobre o tema, e também na busca de dados sobre a chegada de imigrantes, tanto por parentes como por insti-

Resumo: Este texto expōe algumas características do Memorial do Imigrante, instituição pública voltada à memória, à história e à cultura, e seus objetivos e estratégias para alcançá-los, tendo como base alguns preceitos da atividade museológica. $\mathrm{O}$ autor faz uma reflexão sobre a função social de um museu e o envolvimento de funcionários e público na manutenção e desenvolvimento de um sistema bidirecional na comunicação entre os envolvidos, com uma participação equitativa das partes.

Palavras-chaves: museus, preservação, patrimônio, ensino, imigração, Memorial do Imigrante tuições, como a Polícia Federal, arquivos, Cruz Vermelha etc.

Esses trabalhos são integrados a cada um dos quatro setores (Museu, Núcleos e Centro) do Memorial do Imigrante. Agindo dessa maneira, as potencialidades de cada uma das partes pode ser explorada, cumprindo suas funções de preservação e divulgação, sem desperdícios e otimizando a comunicação, tanto interna quanto externa. Como uma instituição pública, consciente de sua importância e das responsabilidades decorrentes, é política do Memorial do Imigrante bem atender nossos visitantes e usuários. Trata-se, na verdade, de um profundo respeito ao nosso público, afinal o Memorial existe em função dessas pessoas. De você, de mim, enfim, de todos nós.

Funcionando à Rua Visconde de Parnaíba, 1316 - Mooca, o Memorial do Imigrante recebe visitas individuais e de escolas de terça-feira a domingo, das $10 \mathrm{~h}$ às $17 \mathrm{~h}$. Mais informações podem ser obtidas em nosso site na Internet: http:/ /www.memorialdoimigrante.sp.gov.br

\section{("Memorial do Imigrante" - a museum in movement)}

Abstract: This text exposes a few characteristics of the Memorial do Imigrante (the Immigrant Memorial), a public institution dedicated to memory, history and to culture, and to its objectives and strategies to reach them, based on a few precepts of the museological activity. The author reflects on the social function a museum has and on employee and public involvement in maintaining and developing a bi-directional system in communications aimed at all involved, with an equitative participation of all parts.

Key words: museums, preservation, assets, teaching, immigration, Memorial do Imigrante 